\title{
Human gender differences in an emotional visual oddball task: an event-related potentials study
}

\author{
S. Campanella ${ }^{\text {a } *}$, M. Rossignol ${ }^{\text {a }}$, S. Mejias ${ }^{\text {a }}$, F. Joassin ${ }^{\text {a }}$, P. Maurage ${ }^{\text {a }}$, \\ D. Debatisse ${ }^{b}$, R. Bruyer ${ }^{a}$, M. Crommelinck ${ }^{c}$, J.M. Guérit $^{\mathrm{d}}$ \\ ${ }^{a}$ Université Catholique de Louvain, Faculté de Psychologie-Unité NESC, Place du Cardinal Mercier, 10, B-1348 Louvain-la-Neuve, Belgium \\ ${ }^{\mathrm{b}}$ Neurosurgical and Neurophysiological EEG Monitoring Unit, CHUV Lausanne, Switzerland \\ ${ }^{c}$ Laboratory of Neurophysiology, Catholic University of Louvain, Brussels, Belgium \\ ${ }^{\mathrm{d}}$ Catholic University of Louvain, NCHM Unit, Brussels, Belgium
}

Received 6 November 2003; received in revised form 20 April 2004; accepted 18 May 2004

\begin{abstract}
Pictures from the Ekman and Friesen series were used in an event-related potentials study to define the timing of occurrence of gender differences in the processing of positive (happy) and negative (fear) facial expressions. Ten male and 10 female volunteers were confronted with a visual oddball design, in which they had to detect, as quickly as possible, deviant happy or fearful faces amongst a train of standard stimuli (neutral faces). Behavioral results suggest that men and women detected fearful faces more quickly than happy ones. The main result is that the $\mathrm{N} 2 \mathrm{~b}$ component, functionally considered as an attentional orienting mechanism, was delayed in men for happy stimuli as compared with fearful ones. Gender differences observed in the processing of emotional stimuli could then originate at the attentional level of the information processing system.
\end{abstract}

(C) 2004 Elsevier Ireland Ltd. All rights reserved.

Keywords: Gender differences; Emotion; Event-related potentials; Oddball design

Several recent studies have suggested that gender differences in emotional processing, most notably reflected in greater male aggression, may have neuro-anatomical correlates $[9,13,15,20]$. By examining temporo-limbic and prefrontal structures with quantitative magnetic resonance imaging (MRI), Gur et al. showed that women have larger orbital frontal cortices than men, resulting in highly significant difference in the ratio of orbital to amygdala volume [9]. Canli et al. used functional MRI to demonstrate stronger right amygdala activation in men and left amygdala activation in women when subjects remembered unpleasant pictures. Wrase et al. found that direct exposure to emotional pictures led, in men, to amygdala activation in the pleasant condition, whereas women showed stronger activation for affectively negative pictures in the anterior and medial cingulate gyrus [4,20]. It is therefore argued that: (1) gender differences should be taken into account when emotional

\footnotetext{
* Corresponding author. Tel.: +32 10 473808; fax: +32 10473774 .

E-mail address: Salvatore.Campanella@psp.ucl.ac.be (S. Campanella).
}

paradigms are used in brain imaging studies; and (2) these different neural pathways devoted to emotional modulation may relate to behavioral evidence for sex differences in emotion processing $[9,20]$.

Only a few brain imaging studies have tried to localize the different brain networks associated with emotion processing in women and men $[9,13,15,20]$. One of the fundamental issues in emotion and gender research is that the same visual stimuli elicit different levels of arousal and valence in men and women [20]. As neuro-anatomical differences could cause behavioral differences between women and men in emotional studies, we think that it would be relevant to define when these differences occur in the information processing system. Due to their excellent temporal resolution, event-related potentials (ERPs) allow us to investigate the temporal course of the various stages implied in a cognitive function [17]. In the present study, we explore, for the first time to our knowledge, the attentional or decisional origin of the behavioral differences evidenced by women and men when confronted with positive or negative emotional facial expressions. 
To do so, we used a variation of the visual oddball paradigm, in which subjects were confronted with one frequent stimulus (a neutral face) and two deviant ones they have to detect as quickly as possible (a happy and a fearful face). Most ERP studies have used an "oddball" paradigm, in which subjects are asked to detect, amongst a series of standard stimuli, an infrequent deviant one. The detection of stimulus change may play a role in directing attention to events of biological importance [10]. This is indexed by two main ERP components. First, when subjects are placed in attentive conditions, deviant visual stimuli evoke a N2b component, peaking at occipital electrodes around $250 \mathrm{~ms}$, which indicates a switch of attention to biologically significant events in order to cope with them [5,10]. Second, a P3b component is maximally recorded at parietal sites around $450 \mathrm{~ms}$, which is functionally related to later conscious, decisional and premotor response-related stages [3,5]. In other words, using ERPs in this emotional detection task will allow us to separate the attentional (preparation-to-process) and the response-related (preparation-to-respond) steps implied during the task. Our principal aim is then to define the level of the information processing system (attentional or decisional) at which the differences observed when women and men are confronted with happy and fearful stimuli originate. An effect circumscribed to response-related stages (decision-making, response premotor preparation) will imply a modulation of the P3b component, but not of the attentional $\mathrm{N} 2 \mathrm{~b}$ (indeed, motor potentials contaminate $\mathrm{P} 3 \mathrm{~b}$ by inducing amplitude reduction and/or double peaking, but probably not earlier components; [14]). However, a behavioral effect originating at the attentional level and extending to behavioral responses will affect both components (N2b and P3b modulations) (see [10] for a review of these components).

Ten men (mean age: 25.9; S.D.: 1.96) and 10 women (mean age: 23.5 ; S.D.: 3.24) $(t(9)=-1.9$; NS), all right-handed, participated in this ERP experiment to explore gender differences in the time course of emotional information processing. As women are more prone to suffer from affective disorders [13], which could alter emotion recognition [16], we matched the male and female participants in the present study on their scores on the 13-items Beck Inventory Depressive Scale (mean for men: 2.1, S.D.: 2.18; women: 3.2, S.D.: $2.86 ; t(9)=0.736$; NS) and on the Spielberger Anxiety Inventory-Trait (mean for men: 40, S.D.: 6.03; women: 45, S.D.: 11.15; $t(9)=1.400$; NS) $[1,18]$. Four faces (two females) with neutral, happy and fearful expressions were selected from the highly standardized set of pictures of Ekman and Friesen series (actors PE, $\mathrm{JJ}, \mathrm{MO}$ and PF) [8].

Subjects were confronted with a total of 16 blocks (four blocks each repeated four times) that were defined by 100 stimuli (84 frequent stimuli: for instance, face A neutral; 8 deviant face A happy; 8 deviant face A fear). The order of the 16 blocks varied across subjects. During the ERPs recording, subjects sat on a chair in a dark room with their head restrained in a chin rest and placed at $1 \mathrm{~m}$ from the screen. Stimuli subtended a visual angle of $3^{\circ} \times 4^{\circ}$. Faces were presented for $500 \mathrm{~ms}$. A black screen was displayed as intertrial interval, lasting randomly between 1300 and $1600 \mathrm{~ms}$, but the subject had $1500 \mathrm{~ms}$ to answer since the stimulation onset. The participants had to point out as quickly as possible the occurrence of a deviant stimulus by pressing a button with their right index finger. The EEG was recorded by 32 electrodes mounted in an electrode Quick-Cap. Electrode positions included the standard 10-20 system locations and intermediate positions. Recordings were made with a linked mastoid physical reference. The EEG was amplified by battery-operated SYNAMPS amplifiers with a gain of 30,000 and a band-pass of $0.01-100 \mathrm{~Hz}$. The impedance of all electrodes was kept below $20 \mathrm{k} \Omega$. EEG was continuously recorded (sampling rate $500 \mathrm{~Hz}$, Neuroscan) and trials contaminated by EOG artifacts (mean of 15\%) were eliminated off-line. Epochs beginning $150 \mathrm{~ms}$ prior to stimulus onset and continuing for $850 \mathrm{~ms}$ were created. Two parameters were coded for every stimulus: (1) the type of the stimulus (rare happy, rare fear, or frequent (where only the frequent stimuli preceding the deviant ones were counted so as to have the same total number of averaged frequent stimuli)); and (2) the response type (keypress for deviant stimuli, no keypress for frequent ones). This coding allowed us to compute different averages of ERP target stimuli for each subject individually. Data were filtered with a $30 \mathrm{~Hz}$ low-pass filter.

As the performance was correct at $98 \%$, only correct response latencies were statistically analyzed with Systat $5.1^{\circledR}$. At selected electrodes ( $\mathrm{Oz}$ for $\mathrm{N} 2 \mathrm{~b}, \mathrm{Pz}$ for $\mathrm{P} 3 \mathrm{~b}$ ), individual peak amplitudes and maximum peak latencies were obtained separately for the ERPs resulting from the subtraction of waveforms evoked by standard and deviant stimuli. These values were tested using repeated measures of ANOVAs and paired Student $t$-tests.

Behavioral results are presented in Table 1 . We computed a $2 \times 2$ ANOVA with gender (male, female) as between fac-

Table 1

Behavioral and ERP results (S.D.)

\begin{tabular}{|c|c|c|}
\hline & Rare happy faces & Rare fear faces \\
\hline \multicolumn{3}{|c|}{ Behavioral data } \\
\hline Women & $425 \mathrm{~ms}$ (S.D. 53) & 404 ms (S.D. 46) \\
\hline Men & $431 \mathrm{~ms}$ (S.D. 37) & 397 ms (S.D. 37) \\
\hline \multicolumn{3}{|c|}{$\mathrm{N} 2 \mathrm{~b}$ latency $(\mathrm{Oz})$} \\
\hline Women & 237 ms (S.D. 37) & $230 \mathrm{~ms}$ (S.D. 26) \\
\hline Men & $259 \mathrm{~ms}$ (S.D. 27) & $238 \mathrm{~ms}$ (S.D. 21) \\
\hline \multicolumn{3}{|c|}{$\mathrm{P} 3 \mathrm{~b}$ latency $(\mathrm{Pz})$} \\
\hline Women & 444 ms (S.D. 53) & $428 \mathrm{~ms}$ (S.D. 46) \\
\hline Men & $460 \mathrm{~ms}$ (S.D. 47) & 442 ms (S.D. 48) \\
\hline \multicolumn{3}{|c|}{$\mathrm{N} 2 \mathrm{~b}$ amplitude $(\mathrm{Oz})$} \\
\hline Women & $-3.05 \mathrm{mV}$ (S.D. 1.8) & $-3.85 \mathrm{mV}$ (S.D. 1.6) \\
\hline Men & $-3.14 \mathrm{mV}$ (S.D. 2.1) & $-4.09 \mathrm{mV}$ (S.D. 2.8) \\
\hline \multicolumn{3}{|c|}{ P3b amplitude $(\mathrm{Pz})$} \\
\hline Women & $7.90 \mathrm{mV}$ (S.D. 2.1) & $9.82 \mathrm{mV}$ (S.D. 1.8) \\
\hline Men & $6.83 \mathrm{mV}$ (S.D. 2.4) & $7.79 \mathrm{mV}$ (S.D. 1.9) \\
\hline
\end{tabular}


tor and emotion (happy, fear) as within factor. This showed no main effect of gender $(F(1,18)=0.001$; NS) but a significant main effect of emotion $(F(1,18)=103,569 ; P$ $<0.0001)$ and a significant interaction $(F(1,18)=5,502$; $P=0.031)$. This suggests that both sexes detected fearful faces more quickly than happy ones (men: $t(9)=10.423 ; P$ $<0.0001$; women: $t(9)=4.984 ; P=0.001$ ), but that this difference was larger in men (mean difference between fear and happy faces: $34 \mathrm{~ms}$ for men, $21 \mathrm{~ms}$ for women) $(t(9)$ $=-2.488 ; P=0.035$ ).

ERP results are illustrated by Fig. 1, that shows, for men and women separately, the difference-waveform and the topographies obtained when we subtract the ERPs in response to frequent stimuli from those obtained in response to the deviants. Two main components, classically described in this kind of visual oddball design, are observable: (1) the N2b component, maximally recorded at occipital sites around $230 \mathrm{~ms}$; and (2) the P3b component, maximally recorded at parietal sites around $450 \mathrm{~ms}[3,5]$.

In women, the $\mathrm{N} 2 \mathrm{~b}$ component reached its maximum peak value at occipital sites $(\mathrm{Oz})$ around $237 \mathrm{~ms}$ for rare happy faces and around $230 \mathrm{~ms}$ for rare fear ones. The correspondent values for men were $259 \mathrm{~ms}$ for rare happy faces and $238 \mathrm{~ms}$ for rare fear ones. Statistical results were summarized in Table 2. For latency values, the analyses suggest that the maximum $\mathrm{N} 2 \mathrm{~b}$ peak amplitude had at a later latency for rare happy face than for rare fear face, but only for men. There was only one significant effect for the maximum amplitude values, i.e. a main effect of emotion, showing, for both sexes, a higher amplitude for the $\mathrm{N} 2 \mathrm{~b}$ component in response to rare fear faces than to rare happy ones.

In women, the P3b component was maximally recorded at parietal sites $(\mathrm{Pz})$ around $444 \mathrm{~ms}$ for rare happy faces and $428 \mathrm{~ms}$ for rare fear ones. In men, this component was recorded around 460 and $442 \mathrm{~ms}$ for rare happy and rare fear faces, respectively. Statistical analyses reveal a main effect of emotion, for both peak maximum latency and peak maximum amplitude value. As no main effect of gender nor interaction (emotion $\times$ gender) was shown, this suggests that the P $3 \mathrm{~b}$ component has a greater amplitude and an earlier onset latency for rare fear faces than for rare happy ones, independently of the subjects' gender.

The first important result of the present study is that women as well as men show faster responses to fearful facial expressions than to happy ones. This was neurophysiologically indexed as follows: on the one hand, we obtained a posterior $\mathrm{N} 2 \mathrm{~b}$ component, reflecting the degree of voluntary attention related to visual information processing during a target detection task $[5,10]$. The $\mathrm{N} 2 \mathrm{~b}$ was both enhanced in amplitude and of shorter latency for fearful stimuli. As facial muscles are differently involved in the production of happy and fearful expressions [8], it could be that the physical differences between neutral and fearful faces are more important than physical differences between neutral and happy ones. This could lead subjects to detect more quickly the physical differences related to the fearful facial expression.
However, even if this stimulus-like effect cannot be entirely discarded, we suggest that the enhanced $\mathrm{N} 2 \mathrm{~b}$ component evoked by fearful faces may have been due to increased attention directed to potentially threatening information. Indeed, several recent studies have suggested that some neural responses to fear signals in faces may take place in a relatively automatic way, providing support for a critical role of this fear system in fast adaptive behavior to threats [19]. A principal role is suggested for the amygdala, which could play some role in tuning the visual system to become more sensitive to threat cues by means of efferent projections to primary sensory areas $[6,7,12]$. Thus, the greater attentional resources devoted to fearful faces can be considered as adaptive, as it is important to correctly identify fear in order to understand what is at stake and how to cope with it. On the other hand, we also obtained, for both sexes, a parietal P3b component, which was functionally related to several psychological concomitants (such as decision-making, premotor response preparation, context updating). This component showed a greater amplitude and an earlier peak latency for fearful faces than for happy ones, indicating a complete consistency between behavioral and neurophysiological data. Indeed, a behavioral delay was obtained for response latencies, suggesting that fearful stimuli are detected faster than happy ones. ERP correlates of this behavioral effect are defined by a delay in the P3b component (reflecting the response-related stage), that originated in the greater attentional resources (reflected by a N2b of greater amplitude and shorter latency onset) devoted to fearful faces.

The second important result is the gender difference observed in the processing of happy stimuli. As mentioned above, the N2b component reflects an attentional stage of the information processing system that can be defined by a latency value based on its maximal peak amplitude. However, we observe that while women and men do not differ in the latency of the $\mathrm{N} 2 \mathrm{~b}$ component for fearful faces (mean for men: $238 \mathrm{~ms}$; women: $230 \mathrm{~ms}$ ), there is a significant gender difference in the delay for happy ones (mean men: $259 \mathrm{~ms}$; women: $237 \mathrm{~ms}$ ). In other words, at the attentional level, women respond equally quickly to happy and fearful faces, whereas men react significantly slowly (mean of $22 \mathrm{~ms}$ ) to happy stimuli.

Then, we are confronted with a particular "latency" effect: the attentional process of happy and fearful faces (reflected by the N2b component) reached, at the same moment, its maximal amplitude in women, while it was significantly delayed for happy faces in men. Our study may indicate that men allocate more attentional resources to threatening information, while women show a more sensitive attentional processing to emotional faces in general (positive and negative emotional facial expressions). This finding could help us to understand why women react more strongly and positively to social support than men do [2]. Indeed, recent developments in understanding the psychosocial aspects of depression linked the well-known gender difference in depressive prevalence with styles of support-seeking/support-giving, 

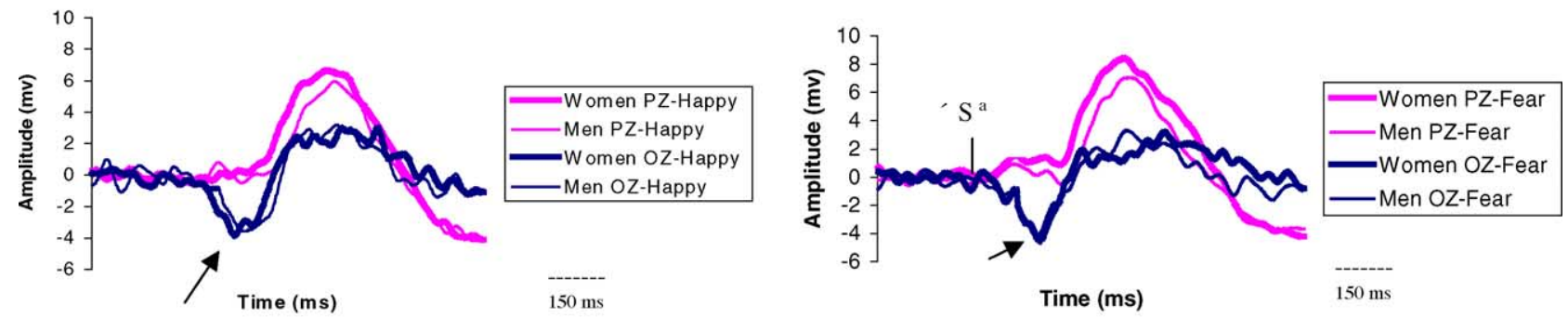

(A)

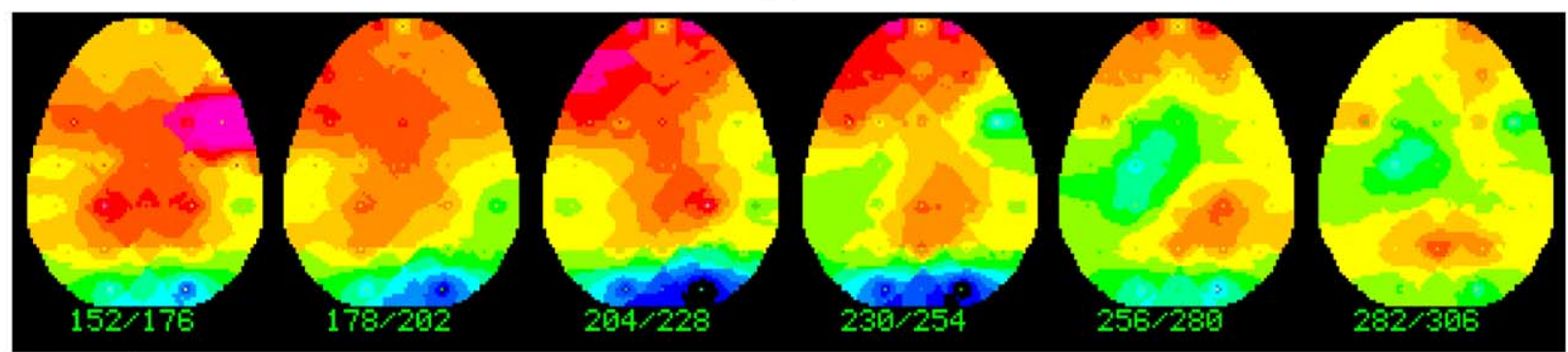

Fear: Women

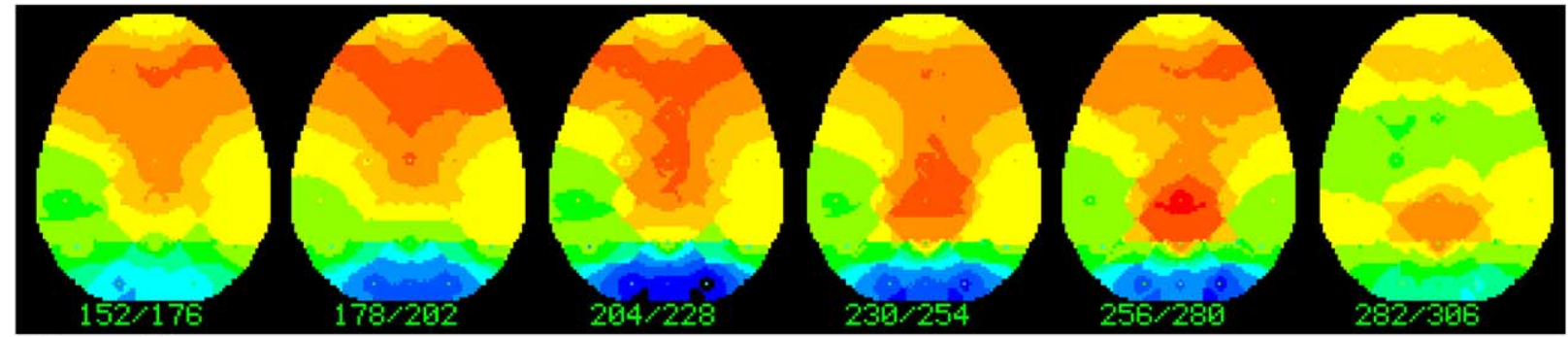

Happy: Women

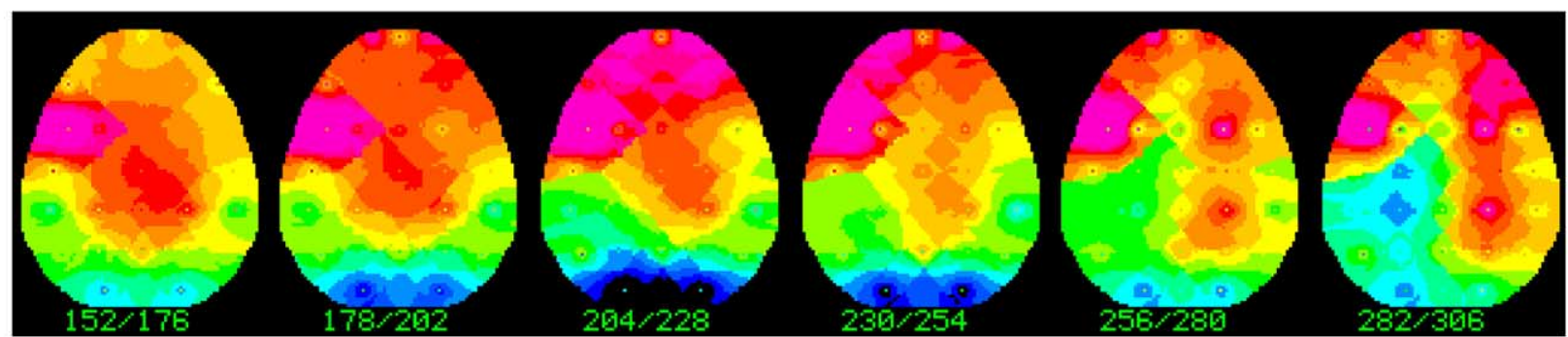

Fear: Men

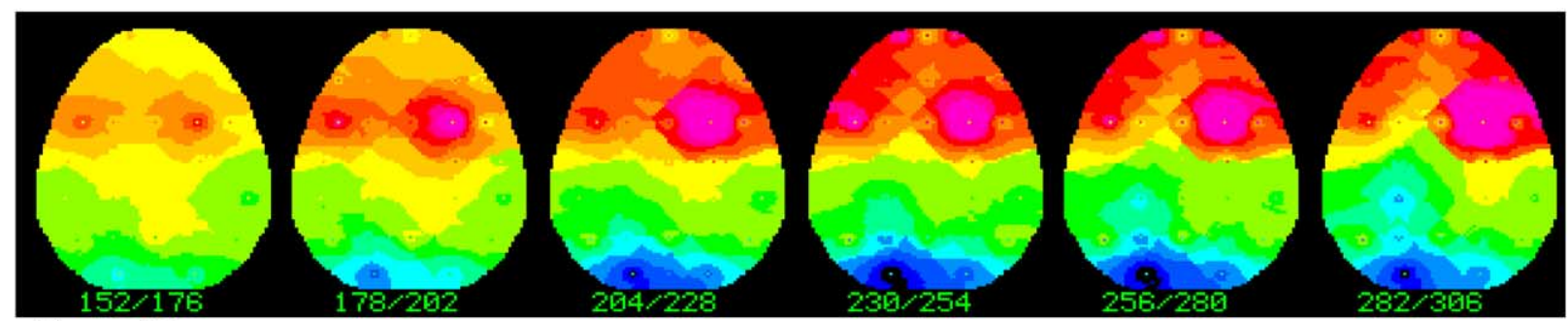

Happy: Men

(B)

Fig. 1. (A) Waveforms (N2b and P3b) obtained, for women and for men, in response to deviant happy stimuli. Note the delay in the generation of the N2b component for men. "S": stimulus onset. (B) Brain topographies recorded from men happy, men fearful, women happy and women fearful faces from 150 to $300 \mathrm{~ms}$ (six levels of $25 \mathrm{~ms}$ ). Red colors represented positivities and blues ones negativities (used scale: -4 to $4 \mathrm{mV}$ ). Note the generation of the N2b component (blue color) at occipital sites and of the P3b (red color) at centro-parietal ones. It could be observed that N2b and P3b components generate darker colors (greater amplitudes) for fear stimuli than happy ones. Moreover, the maximal N2b amplitude was recorded for men fearful faces, women happy faces and women fearful faces at brain map number 3 (between 204 and $228 \mathrm{~ms}$ ) while this moment was significantly delayed for men happy faces (brain maps number 4 and 5). 
Table 2

Synthesis of significant statistical results obtained on the N2b and P3b components by using a $2 \times 2$ ANOVA with gender (male, female) as between-factor and emotion (happy, fear) as within-factor

\begin{tabular}{lll}
\hline & ANOVA $2 \times 2$ & Paired Student $t$-tests \\
\hline N2b latency & Main effect of emotion: $F(1,18)=18.607, P<0.0001$ & Happy vs. fear: men, $t(9)=5.504 ; P<0.0001$ \\
& Interaction emotion $\times$ gender: $F(1,18)=4.584 ; P=0.046$ & Happy vs. fear: women, $t(9)=1.341 ;$ NS \\
N2b amplitude & Main effect of emotion: $F(1,18)=4.997 ; P=0.038$ & - \\
P3b latency & Main effect of emotion: $F(1,18)=37.699 ; P<0.0001$ & - \\
P3b amplitude & Main effect of emotion: $F(1,18)=8.872 ; P=0.008$ & - \\
\hline
\end{tabular}

Paired Student t-tests were used to investigate for significant interactions.

which implied some non verbal communication (such as through facial expressions) and are more pronounced in women [11]. Further studies are needed to address this issue and to confirm these preliminary results.

Overall, brain imaging studies have shown that pleasant and unpleasant visual stimuli activated different neuronal structures in women and men $[9,13,15,20]$. By using ERPs, (1) we confirmed these neural differences by showing modulations of ERP components due to gender; and (2) we gave a functional and a temporal relevance to these differences by suggesting they originated at the attentional level (N2b component) of the information processing system. We suggest that these modulations are due to emotional content, and not to the physical differences of our stimuli which would not generate per se differences between men and women. This may be important in understanding how women react (as compared to men) to emotional material in their environment, and why they are more prone to suffer from affective disorders, such as depression or anxiety.

\section{Acknowledgements}

We would like to thank the Rodin Foundation for financial support, Veronica Gomez Kieffer for her help during ERP recordings and Marie Bronchart for her comments on an earlier version of the paper. The first and the fourth authors are supported by the Belgian fund for scientific research (FNRS).

\section{References}

[1] A.T. Beck, A. Beamesderfer, Assessment of depression: the Depression Inventory. Psychological measurements in psychopharmacology, Mod. Probl. Pharmacopsychiatry 7 (1974) 151-159;

P. Pichot (Ed.), Karger, Basel, Paris, 1974.

[2] T.A. Beehr, S.J. Farmer, S. Glazer, D.M. Gudanowski, V.N. Nair, The enigma of social support and occupational stress: source congruence and gender role effects, J. Occup. Health Psychol. 8 (2003) 220-231.

[3] S. Bentin, Y. Mouchetant-Rostaing, M.H. Giard, J.F. Echallier, F. Pernier, ERP manifestations of processing printed words at different psycholinguistic levels: time course and scalp distribution, J. Cogn. Neurosci. 11 (1999) 235-260.

[4] T. Canli, J.E. Desmond, Z. Zhao, J.D.E. Gabrieli, Sex differences in the neural basis of emotional memories, Proc. Natl. Acad. Sci. U.S.A. 99 (2002) 10789-10794.
[5] S. Campanella, C. Gaspard, D. Debatisse, R. Bruyer, M. Crommelinck, J.M. Guérit, Discrimination of emotional facial expressions in a visual oddball task: an ERP study, Biol. Psychol. 59 (2002) 171-186.

[6] S. Campanella, P. Quinet, R. Bruyer, M. Crommelinck, J.M. Guerit, Categorical perception of happiness and fear facial expressions: an ERP study, J. Cogn. Neurosci. 14 (2002) 210-227.

[7] R.J. Davidson, W. Irwing, The functional neuroanatomy of emotion and affective style, Trends Cogn. Sci. 3 (1999) 11-21.

[8] P. Ekman, W. Friesen, Pictures of Facial Affect, Consulting Psychologists Press, Palo Alto, 1976.

[9] R.C. Gur, F. Gunning-Dixon, W.B. Bilker, R.E. Gur, Sex differences in temporo-limbic and frontal brain volumes of healthy adults, Cereb. Cortex 12 (2002) 998-1003.

[10] E. Halgren, P. Baudena, G. Heit, J.M. Clarke, K. Marinkovic, P. Chauvel, M. Clarke, Spatio-temporal stages in face and word processing. 2. Depth-recorded potentials in the human frontal and rolandic cortices, J. Physiol. 88 (1994) 51-80.

[11] T. Harris, Recent developments in understanding the psychosocial aspects of depression, Br. Med. Bull. 57 (2001) 17-32.

[12] J.E. Ledoux, In search of an emotional system in the brain: leaping from fear to emotion and consciousness, in: M.S. Gazzaniga (Ed.), The Cognitive Neuroscience, MIT Press, Cambridge, MA, pp. 1049-1061.

[13] T.M.C. Lee, L. Ho-Ling, H. Rumjahn, L. Wan-Ting, W. Chien-Te, K.S.L. Yuen, C.C.H. Chan, P.T. Fox, G. Jia-Hong, Gender differences in neural correlates of recognition of happy and sad faces in humans assessed by functional magnetic resonance imaging, Neurosci. Lett. 333 (2002) 13-16.

[14] A. Kok, Overlap between P300 and movement-related-potentials: a response to Verleger, Biol. Psychol. 27 (1988) 51-58.

[15] G. Northoff, A. Richter, M. Gessner, F. Schlagenhauf, J. Fell, F. Baumgart, T. Kaulisch, R. Kotter, K. Stephan, A. Leschinger, T. Hagner, B. Bargel, T. Witzel, H. Hinrichs, B. Bogerts, H. Scheich, H.J. Heinze, Functional dissociation between medial and lateral prefrontal cortical spatiotemporal activation in negative and positive emotions: a combined fMRI/MEG study, Cereb. Cortex 10 (2000) 93-107.

[16] D.R. Rubinow, R.M. Post, Impaired recognition of affect in facial expression in depressed patients, Biol. Psychiatry 31 (1992) 947-953.

[17] M.D. Rugg, M.G.H. Coles, Electrophysiology of Mind. Event-Related Brain Potentials and Cognition, Oxford Psychology Series, 1995, p. 220.

[18] C.D. Spielberger, R.L. Gorsuch, R.E. Lusthene, Manual for the State-Trait Anxiety Inventory, Consulting Psychologist Press, Palo Alto, 1983.

[19] P.J. Whalen, S.L. Rauch, N.L. Etcoff, S.C. McInerney, M.B. Lee, M.A. Jenike, Masked presentations of emotional facial expressions modulate amygdala activity without explicit knowledge, J. Neurosci. 18 (1998) 411-418.

[20] J. Wrase, S. Klein, S.M. Gruesser, D. Hermann, H. Flor, K. Mann, D.F. Braus, A. Heinz, Gender differences in the processing of standardized emotional visual stimuli in humans: a functional magnetic resonance imaging study, Neurosci. Lett. 348 (2003) 41-45. 